\title{
Empirical Study on the Technical Linkage and Spread Effect of China's Construction Industry
}

\author{
Mingyuan Liu \\ School of Economics and Trade \\ Fujian Jiangxia University \\ Fuzhou, China 350108
}

\author{
Minshu Lin \\ School of Economics \\ Xiamen University \\ Xiamen, China 361005
}

\begin{abstract}
The construction industry is one of the investment-driven final demand industries that plays a significant role in China's economic growth in terms of its huge scale of investment in fixed assets and the accelerated growth of added value. This paper makes an in-depth analysis of the cross-industrial technical linkage and spread effect based on the Input-Output model. The model measurement results show the years from 2000 to 2014 has witnessed the yearly increase of China's construction industry backward linkage effect and spread effect, as well as the improving of the industrial strategic position. But as final demand industry, its influence and reaction coefficient is less than the intermediate demand industry, and the forward linkage effect is not significant. Through international comparison, it is discoved in the high income level countries like the United States, Germany, Japan, the spread effect is less than in china, and that the dependence coefficient of all representative countries is ranked first in all industries. In order to adapt to the new normal of China's economic development, we should strengthen the technical linkage between the construction industry and other industries, improve the total factor productivity and production quality of construction industry.
\end{abstract}

Keywords-construction industry; industrial technical linkage; industrial spread effect; input-output model

\section{INTRODUCTION}

The construction industry is an economic activities collection of the company which engages in the structures, housing construction and equipment installation and related activities, and is the secondary industry the same as the mining and quarrying, electricity, gas, steam and air conditioning supply industry. The construction industry usually has the characteristics of strong radiation, weak restriction and long industrial chain (Tiantu Liao, et al, 2012)[1],becomes one of the pillar industries and is becoming more and more important to the national economy development in the evolution process of the industrial structure.

As regards china's construction industry and its technical linkage problems, many scholars have paid attention to and obtained lots of research achievements from. Shenjun Qi, Yunbo Zhang (2012) thought the construction industry was a typical strong impact and high emission industry which made other industries produce huge carbon emissions [2]. Yujie Lu, et al(2016), Jingke Hong, et al (2017), Mohammed, et al(2017) analyzed the characteristics, energy consumption, development driving power of the construction industry from the perspectives of carbon emissions and its policy, energy demand, linear and circular supply chain[3,4,5]. Bingsheng Liu and Bin Xue (2015) analyzed the regional spatial differences of China's construction industry based on such three dimensions as development, competition and cooperation association [6].Ying Liu, et al (2016) empirically analyzed the linkage between the construction industry and other industries by grey relational model. The results showed that the construction industry has a high linkage with other 17 industries [7]. These research achievements provide a good way of thinking and methods for future studies in construction industry, especially for the industrial technical linkage.

Under the new normal of China's economic development, Chinese industry development speed has slowed down and industry structural problems have become increasingly prominent. Therefore, on the basis of the existing research, this paper will use the Input-Output model to make an indepth analysis of the technical economic linkage and spread effect between construction industry and other industries, and puts forward a new idea and countermeasures in order to promote the industrial development and improve the construction industry production quality, so as to increase its contribution to the national economy development.

\section{DEVELOPMENT AND CHARACTERISTICS OF CHINA'S CONSTRUCTION INDUSTRY}

China's GDP was 74.41 trillion yuan in 2016, of which the fixed capital formation was 31.89 trillion yuan, accounting for 44.2 percent of China's GDP. Obviously the investment-driven was the main mode of China's economic growth. The data show that the scale of total fixed assets investment was 60.69 trillion yuan in 2016, an increase of $7.9 \%$, of which the scale of the urban fixed assets investment was 59.65 trillion yuan, the secondary industry was 23.20 trillion yuan, the construction industry was 0.46 trillion yuan, respectively accounting for $98.35 \%, 38.25 \%, 0.76 \%$ of the total fixed asset investment. As one of the investment-driven industries, to a certain extent, the construction industry's contribution to China's economic growth depends on the scale of its investment demand. 
With the expansion of the construction industry scale and the advancement of the industrialization process, the investment demand of the construction industry is increasing, and the internal economic relationship between the construction industry and other industries as well as the contribution power of the construction industry to national economic growth is enhancing. In order to deal with the global economic crisis erupted in 2008 and its impact on economic development, Chinese government launched a "four trillion" investment plan. Under the stimulus of the "four trillion" investment plan, Chinese construction industry have grown rapidly, in 2009 the growth rate was $18.9 \%$ that reached the highest point, and since then the growth rate has declined. The data also show the total output, the added value, the number of employees and company of the construction industry continued to develop during the period of 2008-2016 in "Table I". As of 2016, the total output reached 19.36 trillion yuan, the added value 4.95 trillion yuan, and the number of employees 51.85 million, the number of companies 83 thousand, of which the added value accounted for about $6.6 \%$ of the GDP.

TABLE I. ChINA'S CONSTRUCTION INDUSTRY DEVELOPMENT SituATION

\begin{tabular}{|l|l|l|l|l|l|l|}
\hline Year & $\begin{array}{c}\text { Total output value } \\
\text { (Trillion) }\end{array}$ & $\begin{array}{c}\text { Added value } \\
\text { (Trillion) }\end{array}$ & $\begin{array}{l}\text { Added value percent } \\
\text { of GDP (\%) }\end{array}$ & $\begin{array}{l}\text { Growth rate } \\
(\%)\end{array}$ & $\begin{array}{c}\text { Employees } \\
\text { (Ten thousand) }\end{array}$ & $\begin{array}{c}\text { Number of } \\
\text { company } \\
\text { (Ten thousand) }\end{array}$ \\
\hline 2008 & 6.20 & 1.88 & 5.9 & 9.5 & 3315.0 & 7.1 \\
\hline 2009 & 7.68 & 2.27 & 6.5 & 18.9 & 3672.6 & 7.1 \\
\hline 2010 & 9.60 & 2.73 & 6.6 & 11.3 & 4160.4 & 7.2 \\
\hline 2011 & 11.65 & 3.29 & 6.7 & 9.7 & 3852.5 & 7.2 \\
\hline 2012 & 13.72 & 3.69 & 6.8 & 9.8 & 4267.2 & 7.5 \\
\hline 2013 & 16.04 & 4.09 & 6.9 & 9.7 & 4528.4 & 7.9 \\
\hline 2014 & 17.67 & 4.49 & 7.0 & 9.1 & 4537.0 & 8.1 \\
\hline 2015 & 18.08 & 4.65 & 6.8 & 6.8 & 5093.7 & 8.1 \\
\hline 2016 & 19.36 & 4.95 & 6.6 & 6.7 & 5184.5 & 8.30 \\
\hline
\end{tabular}

In order to have more insight into the development of the construction industry, the paper will solve the first and second order difference of the total output and the added value of the construction industry to analyze the growth trend and speed change. The analysis results show that during the period of 2008-2016, the first order difference of the total output and the added value is greater than zero, indicating that the construction industry maintained a steady growth trend in this period. The second order difference of the total output was greater than zero during 2008-2013, indicating that the growth speed of the total output accelerated, but the growth speed began to decline from 2014. The second order difference of the added value is greater than or equal to zero except 2012 and 2016, indicating that the added value growth speed accelerated overall.

$\left\{\begin{array}{l}x_{11}+x_{12} \cdots+x_{1 n}+y_{1}=x_{1} \\ x_{21}+x_{22} \cdots+x_{2 n}+y_{2}=x_{2} \\ \cdots \cdots \\ x_{n 1}+x_{n 2} \cdots+x_{n}+y_{n}=x_{n}\end{array} ; \quad Z=\left[\begin{array}{c}x_{11}+x_{12}+\cdots \cdots+x_{1 n} \\ x_{21}+x_{22}+\cdots \cdots+x_{2 n} \\ \cdots \cdots \\ x_{n 1}+x_{n 2}+\cdots \cdots+x_{n n}\end{array}\right]_{n \times n}\right.$

Here $Z$ refers to the intermediate demand matrix, $X, Y$ respectively refers to the total output and final demand vector, ${ }^{x_{i}}$ refers to the total output of the $i_{\text {industry, }}{ }^{y_{i}}$ refers

\section{THE THEORETICAL MODEL CONSTRUCTION AND DATA PROCESSING}

\section{A. Input-output Model}

The input output model that is composed of the coefficient and variable function is an important tool to measure the industrial technical linkage and spread effect. According to the input-output table in value form, row vector indicates that the industrial total output is composed of intermediate and final demand, while column vector indicates that the industrial total input consists of intermediate and initial inputs. So according to the equilibrium relationship of the input-output table, the inputoutput model is constructed as follows:

$X=\left[\begin{array}{l}x_{1} \\ x_{2} \\ \vdots \\ x_{n}\end{array}\right]_{n \times 1} ; Y=\left[\begin{array}{l}y_{1} \\ y_{2} \\ \vdots \\ y_{n}\end{array}\right]_{n \times 1}$

to the final demand of the $i$ industry. If the direct requirements coefficient matrix $A$ is introduced, the inputoutput model can be expressed as follows:

$$
\begin{gathered}
Y=(I-A) X \Rightarrow X=(I-A)^{-1} Y \\
A=\left[\begin{array}{c}
a_{11}+a_{12}+\cdots \cdots+a_{1 n} \\
a_{21}+a_{22}+\cdots \cdots+a_{2 n} \\
\cdots \cdots \\
a_{n 1}+a_{n 2}+\cdots \cdots+a_{n n}
\end{array}\right]_{n \times n} ; I=\left[\begin{array}{cccc}
1 & 0 & \cdots & 0 \\
0 & 1 & \cdots & 0 \\
\vdots & \vdots & \vdots \\
0 & 0 & \cdots & 1
\end{array}\right]_{n \times n} ; C=(I-A)^{-1}=\left[\begin{array}{cccc}
b_{11}+1 & b_{12} & \cdots & b_{1 n} \\
b_{21} & b_{22}+1 & \cdots & b_{2 n} \\
\vdots & \vdots & & \vdots \\
b_{n 1} & b_{n 2} & \cdots & b_{n n}+1
\end{array}\right]_{n \times n}
\end{gathered}
$$


$a_{i j}$ refers to the elements of the direct consumption matrix that illustrates the direct consumption of $i$ industry for production of $j$ industry, $I$ is $n \times n$ order unit matrix, $(I-A)^{-1}$ is $n \times n$ order Leontief inverse matrix that also known as the input-output multiplier or full demand coefficient matrix to be used for empirical evaluation of industrial linkage and spread effect, $b_{i j}$ is the complete consumption coefficient that includes direct and indirect consumption value and illustrates the complete consumption of $i$ industry for production of $j$ industry. Thus, based on the complete consumption coefficient matrix, the input-output model in matrix form can be expressed as follows.

$$
X=(I-A)^{-1} Y \Leftrightarrow\left[\begin{array}{l}
x_{1} \\
x_{2} \\
\vdots \\
x_{n}
\end{array}\right]=\left[\begin{array}{lrrr}
b_{11}+1 & b_{12} & \cdots & b_{1 n} \\
b_{21} & b_{22}+1 & \cdots & b_{2 n} \\
\vdots & \vdots & & \vdots \\
b_{n 1} & b_{n 2} & \cdots & b_{n n}+1
\end{array}\right]\left[\begin{array}{l}
y_{1} \\
y_{2} \\
\vdots \\
y_{n}
\end{array}\right]
$$

Backward linkage effect

\section{B. Measure Indicators}

1) Industrial linkage measurement indicators: As development economist, Albert O Hirshman put forward the concept of industrial linkage effect in 1958.Based on the industrial chain principle, the industry usually affects and promotes the development of related indus tries through forward and backward linkage, which strengthens the economic interdependence between industries.

As shown in "Fig. 1", the A industry provides intermediate products to the B industry, the B industry is the intermediate inputs of the $\mathrm{C}$ industry. The linkage between the $\mathrm{A}$ industry and the $\mathrm{B}$ industry is named the industrial backward linkage, while the linkage between the B industry and the $\mathrm{C}$ industry is named the industrial forward linkage.

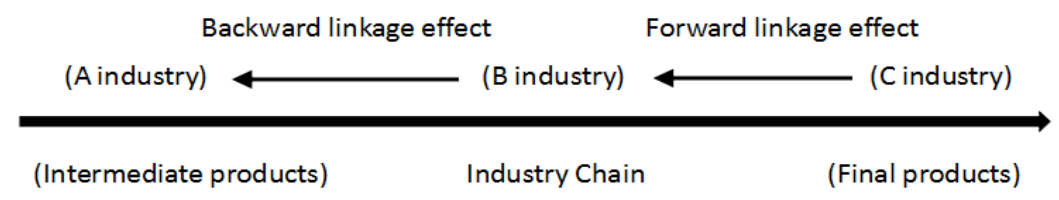

Fig. 1. Industrial chain and industrial linkage.

From the perspective of industrial inputs, consumption coefficient reflects the industrial pulling power for other industries. The distribution coefficient is the proportion of the intermediate demand part of the total output, which reflects the industrial driving power for other industries. In

$$
B=\left[\begin{array}{llll}
b_{11} & b_{12} & \cdots & +b_{1 n} \\
b_{21} & b_{22} & \cdots & +b_{2 n} \\
\vdots & \vdots & & \vdots \\
b_{n 1} & b_{n 2} & \cdots & +b_{n n}
\end{array}\right] ; \quad R=\left[\begin{array}{l}
r_{11} \\
r_{21} \\
\vdots \\
r_{n 1}
\end{array}\right.
$$

Here, the ${ }^{b_{j}}$ and $r_{i}$ indicators can be used to measure the forward and backward linkage effect of different industries. The ${ }^{b_{j}}$ indicator reflects the pulling power of the final demand of different industries, If $b_{j=1}>b_{j=2}$, it shows that the backward linkage effect of the first industry $(j=1)$ is greater than that of the second industry ( $j=2$ ), which is more significant to pulling other industries development. The $r_{i}$ indicator reflects the driving power of the final demand of different industries, If $r_{i=1}>r_{i=2}$, it shows that the forward linkage effect of the first industry $(r=1)$ is greater than that of the second industry $(r=2)$, which is more significant to driving other industries development.

2) Industrial spread effect measurement indicator: Industrial spread refers to that the changes in the industrial scale, technology, influencing factors cause the changes in order to more fully reflect the industrial backward and forward linkage effects, we use the complete consumption coefficient and complete distribution coefficient to measure it. The complete consumption coefficient and the complete distribution coefficient matrix are as follows:

$$
\left.\begin{array}{lcc}
r_{12} & \cdots & +r_{1 n} \\
r_{22} & \cdots & +r_{2 n} \\
\vdots & & \vdots \\
r_{n 2} & \cdots & +r_{n n}
\end{array}\right] ; \quad\left\{\begin{array}{l}
b_{j}=\sum_{i=1}^{n} b_{i j} \quad j=1,2 \ldots . n \\
r_{i}=\sum_{j=1}^{n} r_{i j} \quad i=1,2 \ldots . n
\end{array}\right.
$$

other related industries. The industrial spread effect can be measured by the industrial influence coefficient, reaction coefficient, dependence coefficient and induced coefficient. The four statistical indicators are as follows:

$$
\begin{array}{rlrl}
R_{i} & =\frac{\frac{1}{n} \sum_{j=1}^{n}(I-A)^{-1}{ }_{i j}}{\frac{1}{n^{2}} \sum_{i=1}^{n} \sum_{j=1}^{n}(I-A)^{-1}} & E_{j} & =\frac{\frac{1}{n} \sum_{i=1}^{n}(I-A)^{-1}{ }_{i j}}{\frac{1}{n^{2}} \sum_{i=1}^{n} \sum_{j=1}^{n}(I-A)^{-1}} \\
L_{i l}=\frac{Z_{i l}}{Y_{l}} & Q_{i l} & =\frac{Z_{i l}}{\sum_{i=1}^{n} Z_{i l}} \quad i, j, l=1,2, \ldots \ldots . ., n
\end{array}
$$

In the formula, the $R_{i}$ indicator is the reaction coefficient of the ${ }^{i}$ industry, the ${ }^{E_{j}}$ indicator is the influence coefficient of the $j_{\text {industry, the }} L_{i l}$ indicator is the induced coefficient of the final demand item $l$ of the ${ }^{i}$ industry, the $Q_{i l}$ indicator is the dependence coefficient of the final demand item $l$ of the $i$ industry, $(I-A)^{-1}{ }_{i j}$ is the elements of the Leontief 
inverse matrix,$Z_{i l}$ is the induced amount of the final demand item $l$ of the $i$ industry, $\sum_{i=1}^{n} Z_{i l}$ is the total induced amount of the final demand item ${ }^{l}$ of all industries, ${ }^{l}$ refers to the final demand items of consumption, exports, investment and government spending, $i$ and $j$ refer to industrial type.

3) Data sources and interpretation: The model data are from world input output database (WIOD). In order to make a more comprehensive analysis of the industrial linkage and spread effects of China's construction industry, the latest input-output data in 2014 about the United States, Germany, Japan and India, as well as China's input-output data from 2000 to 2014 will be selected, so as to do horizontally and vertically comparison of the measurement results and analyze the national differences and evolution of China's construction industry linkage and spread effect.
The Leontief inverse coefficient matrix is the coefficient condition to measure the industrial linkage and spread effect. According to the properties of the inverse matrix, if the $\mathrm{N}$ order matrix is invertible, the inverse matrix must be unique. The necessary and sufficient condition for the invertibility of $\mathrm{N}$ order matrix is that the determinant of $\mathrm{N}$ order matrix is not equal to zero, and that the matrix is a full rank square matrix which can be transformed into a unit matrix by elementary row transformation. In order to meet the solving requirements of the Leontief inverse matrix, the data need to be preprocessed, which eliminate the industries with zero data and avoid the problem of pseudo inverse matrix. The original data of input-output table has 56 industries. According to the research needs and the basic requirements of Leontief inverse matrix solving conditions, the 47 effective data industries will be finally selected from 56 industries, as shown in "Table II".

TABLE II. The 47 EFFECTIVE DATA INDUSTRIES

\begin{tabular}{|c|c|c|c|c|c|}
\hline Ser. & Code & Name of industry & Ser. & Code & Name of industry \\
\hline 1 & A01 & $\begin{array}{l}\text { Crop and animal production, hunting and } \\
\text { related service activities }\end{array}$ & 25 & E37-E39 & $\begin{array}{l}\text { Sewerage; waste collection, treatment and disposal activities; } \\
\text { materials recovery; remediation activities and other waste } \\
\text { management services }\end{array}$ \\
\hline 2 & A02 & Forestry and logging & 26 & $\mathrm{~F}$ & Construction \\
\hline 3 & A03 & Fishing and aquaculture & 27 & G46 & Wholesale trade, except of motor vehicles and motorcycles \\
\hline 4 & $\mathrm{~B}$ & Mining and quarrying & 28 & G47 & Retail trade, except of motor vehicles and motorcycles \\
\hline 5 & $\mathrm{C} 10-\mathrm{C} 12$ & $\begin{array}{l}\text { Manufacture of food products, beverages and } \\
\text { tobacco products }\end{array}$ & 29 & H49 & Land transport and transport via pipelines \\
\hline 6 & $\mathrm{C} 13-\mathrm{C} 15$ & $\begin{array}{l}\text { Manufacture of textiles, wearing apparel and } \\
\text { leather products }\end{array}$ & 30 & $\mathrm{H} 50$ & Water transport \\
\hline 7 & C16 & $\begin{array}{l}\text { Manufacture of wood and of products of wood } \\
\text { and cork }\end{array}$ & 31 & H51 & Air transport \\
\hline 8 & C17 & Manufacture of paper and paper products & 32 & H52 & Warehousing and support activities for transportation \\
\hline 9 & C18 & Printing and reproduction of recorded media & 33 & H53 & Postal and courier activities \\
\hline 10 & C19 & $\begin{array}{l}\text { Manufacture of coke and refined petroleum } \\
\text { products }\end{array}$ & 34 & $\mathrm{I}$ & Accommodation and food service activities \\
\hline 11 & $\mathrm{C} 20$ & \begin{tabular}{|l} 
Manufacture of chemicals and chemical \\
products
\end{tabular} & 35 & $\mathrm{~J} 61$ & Telecommunications \\
\hline 12 & $\mathrm{C} 21$ & $\begin{array}{l}\text { Manufacture of basic pharmaceutical products } \\
\text { and pharmaceutical preparations }\end{array}$ & 36 & J62_J63 & $\begin{array}{l}\text { Computer programming, consultancy and related activities; } \\
\text { information service activities }\end{array}$ \\
\hline 13 & $\mathrm{C} 22$ & Manufacture of rubber and plastic products & 37 & K64 & $\begin{array}{l}\text { Financial service activities, except insurance and pension } \\
\text { funding }\end{array}$ \\
\hline 14 & $\mathrm{C} 23$ & $\begin{array}{l}\text { Manufacture of other non-metallic mineral } \\
\text { products }\end{array}$ & 38 & K65 & \begin{tabular}{|l}
$\begin{array}{l}\text { Insurance, reinsurance and pension funding, except } \\
\text { compulsory social security }\end{array}$ \\
\end{tabular} \\
\hline 15 & $\mathrm{C} 24$ & Manufacture of basic metals & 39 & L68 & Real estate activities \\
\hline 16 & $\mathrm{C} 25$ & Manufacture of fabricated metal products & 40 & $\begin{array}{l}\text { M69_M } \\
70\end{array}$ & $\begin{array}{l}\text { Legal and accounting activities; activities of head offices; } \\
\text { management consultancy activities }\end{array}$ \\
\hline 17 & $\mathrm{C} 26$ & $\begin{array}{l}\text { Manufacture of computer, electronic and } \\
\text { optical products }\end{array}$ & 41 & M72 & Scientific research and development \\
\hline 18 & $\mathrm{C} 27$ & Manufacture of electrical equipment & 42 & $\begin{array}{l}\text { M74_M } \\
75\end{array}$ & $\begin{array}{l}\text { Other professional, scientific and technical activities; } \\
\text { veterinary activities }\end{array}$ \\
\hline 19 & $\mathrm{C} 28$ & Manufacture of machinery and equipment n.e.c. & 43 & $\mathrm{~N}$ & Administrative and support service activities \\
\hline 20 & $\mathrm{C} 29$ & $\begin{array}{l}\text { Manufacture of motor vehicles, trailers and } \\
\text { semi-trailers }\end{array}$ & 44 & O84 & Public administration and defence; compulsory social security \\
\hline 21 & $\mathrm{C} 30$ & Manufacture of other transport equipment & 45 & P85 & Education \\
\hline 22 & C31_C32 & Manufacture of furniture; other manufacturing & 46 & Q & Human health and social work activities \\
\hline 23 & D35 & $\begin{array}{l}\text { Electricity, gas, steam and air conditioning } \\
\text { supply }\end{array}$ & 47 & R_S & Other service activities \\
\hline 24 & E36 & Water collection, treatment and supply & & & \\
\hline
\end{tabular}




\section{EMPIRICAL MEASUREMENT AND RESULTS ANALYSIS}

\section{A. Results Analysis of Industrial Linkage Effect}

The column sum of the complete consumption coefficient matrix indicates the pulling effect of a unit of the industrial final demand to incremental value of total output for all other industries that is the backward linkage effect. As shown in "Table III", the industries ranked the top ten backward linkage effects are as follows: C26, C27, C29, C30, $\mathrm{C} 22, \mathrm{C} 20, \mathrm{C} 23, \mathrm{C} 24, \mathrm{C} 28, \mathrm{~F}$ industries. The largest backward linkage effect industry is C26 industry that its backward linkage effect coefficient is 3.021, the smallest is
L67 that its backward linkage effect coefficient is 0.397 . For construction industry, its backward linkage effect coefficient is 2.533 , ranking the 10 th, which indicates that if the final demand of the construction industry is increased by 1 unit, the total output of other industries will be increased by 2.533 units. By the vertical comparison, it is discoved that the backward linkage coefficient of China's construction industry increased from 2.083 in 2000 to 2.533 in 2014, an increase of 0.45 . This indicates the construction industry is playing a more and more important role in pulling and promoting the other industries, especially the backward related industries development.

TABLE III. CHINA'S TOP TEN LINKAGE EFFECT INDUSTRIES IN 2014

\begin{tabular}{|l|l|l|l|l|l|}
\hline \multicolumn{3}{|c|}{ Industrial backward linkage effect coefficient } & \multicolumn{3}{c|}{ Industrial forward linkage effect coefficient } \\
\hline Rank & Idustry & Coefficient & Rank & Idustry & Coefficient \\
\hline 1 & C26 & 3.021 & 1 & B & 5.475 \\
\hline 2 & C27 & 2.989 & 2 & A02 & 4.388 \\
\hline 3 & C29 & 2.926 & 3 & D35 & 3.851 \\
\hline 4 & C30 & 2.827 & 4 & C20 & 3.795 \\
\hline 5 & C22 & 2.813 & 5 & C19 & 3.720 \\
\hline 6 & C20 & 2.808 & 6 & C17 & 3.584 \\
\hline 7 & C25 & 2.787 & 7 & H52 & 3.073 \\
\hline 8 & C24 & 2.730 & 8 & E37-E39 & 3.061 \\
\hline 9 & C28 & 2.720 & 10 & C24 & 3.034 \\
\hline 10 & F & 2.533 & 46 & M69_M70 & 2.997 \\
\hline 47 & L68 & 0.397 & & & 0.167 \\
\hline
\end{tabular}

From the perspective of different industry, the largest pulling effect of the construction industry is for C24 industry which its backward linkage effect coefficient is 0.318 , indicating if the final demand of the construction industry is increased by 1 unit, the total output of C24 industry will be increased by 0.318 units. The smallest pulling effect is for H53 industry which its backward linkage effect coefficient is only 0.002. As shown in "Fig. 2", the top ten backward linkage effects industries are as follows: C24, C23, B, C20, D35, C19, C27, G46, C25, and C16. Obviously the backward linkage industries mainly are manufacturing industry.

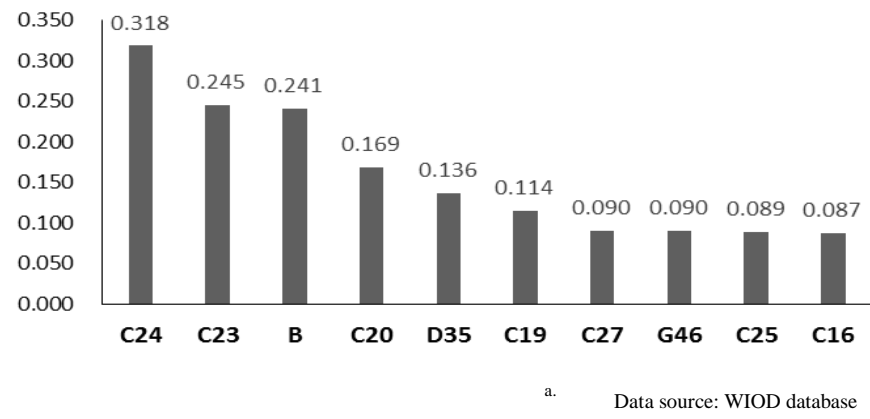

Fig. 2. Top ten backward linkage industries of China's construction industry in 2014 .

The forward linkage effect refers to that the industrial development causes the change of the related industries, or the formation of new industries, or the application of new technologies and new materials. Compared with the backward linkage effect, the forward linkage effect is not significant, its forward linkage effect coefficient is only 0.167 , that is to say if the initial inputs of the construction industry is increased by 1 unit, the total output of all other industries will be increased by 0.167 units. But the impact of the initial inputs of other industries on the construction industry is very significant. The measurement results show that the total output of the construction industry will be increased by 11.695 units if all industries increase 1 unit of initial inputs. That is because the construction industry is a typical investment-driven final demand industry, and the low intermediate demand rate of construction industry also directly affects the forward linkage effect.

\section{B. Results Analysis of Industrial Spread Effect}

Industrial spread intensity and path determine the position and function of the industry in the whole national economy. Practice shows if a certain industrial influence and reaction coefficient is greater than 1 at the same time, the industry affects other related industries directly or indirectly, or significantly affected by other industries. The industry will become the strategic industry, plays an important role on the national economic growth. As shown in "Fig. 3", the results show that the influence coefficient of the construction industry is greater than 1 , to be ranked at the top of the list of the 47 selected industries by tenth. The largest influence coefficient industry is C26 industry which influence coefficient is 1.364 . Relative to the influence coefficient, the reaction coefficient is less than 1 , that is to say the construction industry is less affected by other industries. In 
China, the largest reaction coefficient industries are the manufacturing industry. There are C28, C24, C20, C22, C29, $\mathrm{C} 27, \mathrm{C} 26$ industries which its influence and reaction coefficient are greater than 1. Difference from the construction industry, these industries are not the final demand industry but the intermediate demand industries. The results indicate that as for the influence and reaction coefficient, the final demand industry is generally smaller than the intermediate demand industries.

Investment-driven economic growth mode makes the investment become the core power to promote national economic growth. Data show the proportion of China's capital formation increased from $38.21 \%$ in 1978 to $46.03 \%$ in 2015 in "Fig. 3". So we use the indicator of the industrial dependence and induced coefficient to further analyze the spread effect of the construction industry from the perspective of investment demand. The results show the dependence and induced coefficient of the construction industry respectively is 0.185 and 0.644 . It is the construction industry that whether the induced coefficient or the dependence coefficient are the highest. This further proves the construction industry is the largest investmentdependent industries.

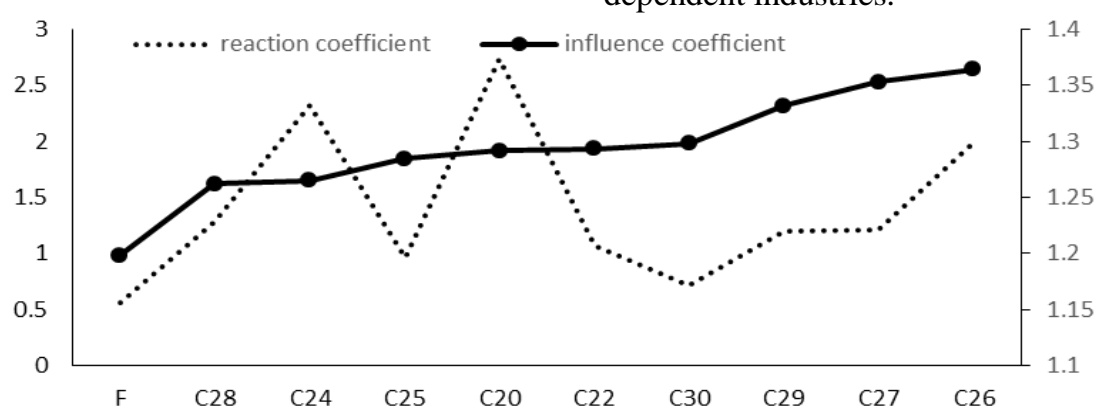

Data source: WIOD database

Fig. 3. The influence and reaction coefficient of China's construction industry.

In 2002, China's per capita GNI was US\$1100, and economic development stage has evoluted from the low income level to the middle income level. In the process of industrialization and economic development, the construction industry has gradually developed into a pillar industry in china. On the one hand it is to adapt to the needs of China's investment-driven economic development, on the other hand it shows that the construction industry has a significant backward linkage effect that produce a strong pulling effect on the development of other related industries. With the development of China's economic development, the scale and influence of the construction industry is yearly increasing. The data show the total output increased from US\$248.69 billion in 2000 to US\$30339 billion in 2014, with an average annual growth rate of $9.80 \%$, accounting for $7.24 \%$ in 2000 to $9.56 \%$ in 2014 of the total output of all the industries.

The results also show that from 2000 to 2014, the influence coefficient, reaction coefficient, dependence coefficient, induced coefficient of china's the construction industry are continuously increasing in "Table IV". From the aspect of countries, India's per capita GNI is $\$ 1590$ in 2015 , according to the GNI standard, India was just across the low income trap into the lower middle income development stage, and the construction industry is becoming the strategic industry that its influence and reaction coefficient are higher than 1.The total output of the construction industry accounts for more than $10.22 \%$ of all the industries, which is higher than $9.56 \%$ of China's total output. The high income developed countries like the United States, Germany and Japan, its industrial structure is led by the tertiary industry. The spread effect coefficient of the construction industry of these countries is smaller than China, ranked after China, and the proportion of total output is lower than China. The results show that the influence coefficient of the United States, Germany and Japan respectively ranked the 22th, 22th, 24th, while China is the tenth. The proportion of total output of construction industry respectively accounts for $4.19 \%$, $5.49 \%, 7.33 \%$ of all the industries, far lower than China. However, the construction industry as an investment-driven final demand industry, whether in middle income level countries like China and India or in high income level countries like the United States, Germany and Japan, the dependence coefficient is ranked first in all industries.

TABLE IV. CONSTRUCTION INDUSTRIAL SPREAD EFFECT OF CHINA AND REPRESENTATIVE COUNTRIES

\begin{tabular}{|l|l|l|l|l|l|}
\hline \multicolumn{1}{|c|}{ Country } & \multicolumn{1}{|c|}{ Year } & \multicolumn{1}{|c|}{$\begin{array}{c}\text { Influence } \\
\text { coefficient }\end{array}$} & $\begin{array}{c}\text { Reaction } \\
\text { Coefficient }\end{array}$ & $\begin{array}{c}\text { Dependence } \\
\text { Coefficient }\end{array}$ & induced Coefficient \\
\hline China & 2000 & 1.142 & 0.593 & 0.188 & 0.578 \\
\hline China & 2014 & 1.199 & 0.567 & 0.185 & 0.644 \\
\hline United States & 2014 & 0.967 & 0.730 & 0.180 & 0.331 \\
\hline Germany & 2014 & 1.031 & 1.294 & 0.204 & 0.409 \\
\hline India & 2014 & 1.173 & 1.191 & 0.290 & 0.684 \\
\hline Japan & 2014 & 1.022 & 0.864 & 0.236 & 0.541 \\
\hline
\end{tabular}




\section{CONCLUSION}

Research shows that there is a significant backward linkage effect between the construction industry and other industries, especially for the intermediate demand manufacturing industries. There is a strong technical and economic relationship between them. Relative to backward linkage effect, the forward linkage effect is weaker, and the reaction coefficient is smaller. Construction industry as investment-driven final demand industry, whether in middle income level countries or in high income level countries, it is the construction industry that the dependence on investment is the highest, so the rapid development of the construction industry can drive investment demand and expand domestic demand. The impact of the construction industry on the national economy is gradually weakened with the economic development, the more developed countries, the lower and the degree of dependence on the construction industry. Accordingly, in order to adapt to the new economic norm and accelerate the transformation and upgrading of the industrial structure, first of all, we should strengthen the technical and economic linkage between the construction industry and other industries, especially the manufacturing industry. Secondly, we should optimize the initial input elements structure through the distribution of products in different industries, make the initial inputs directly or indirectly into the different industrial production process, so as to improve the total factor productivity of the construction industry.

\section{REFERENCES}

[1] Tiantu Liao, Xia-zhu Huang: Analysis on the Industrial Relationship and Ripple Effect of Chinese Construction Industry. Journal of Changchun Univeristy 22(2012),1050-1054.

[2] Bingsheng Liu,Bin Xue:Analysis of the Three-dimensional System of Industry Linkages with Spatial Difference for the Chinese Regional Construction Industry. Journal of Chongqing University 21(2015),1622.

[3] Shen-jun Qi, Yun-bo Zhang: Study on Correlation Properties and Spreading Characteristics of Carbon Emission between Construction Industry and Correlative Industries. Building Science 28(2012),85-89.

[4] Ying Liu,Yu Li,Zhijun Ye:The Correlation Degree Analysis of Construction Industry and Related Industries Based on Grey Relational Model. Journal of Shenyang Jianzhu University 18(2016), 53-57.

[5] Yujie Lu,Peng Cui,Dezhi Li:Carbon emissions and policies in China's building and construction industry: Evidence from 1994 to 2012. Building and Environment 95(2016), 94-103.

[6] Jingke Hong, Zhengdao Li,Qiping Shen,Fan Xue,Bingxia Sun,Wei Zheng:An Overview of the driving forces behind energy demand in China's construction industry: Evidence from 1990 to 2012. Renewable and Sustainable Energy Reviews 73(2017),85-94.

[7] Mohammed Haneef Abdul Nasir,Andrea Genovese, Adolf A. Acquaye, S.C.L. Koh, Fred Yamoah:Comparing linear and circular supply chains: A case study from the construction industry. International Journal of Production Economics 183(2017),443-457. 